\title{
Screening of Aspergillus oryzae M/4 for extra cellular alpha- amylase production
}

\author{
Zh. Suleimenova, Zh. Rakhmetova, A. Zhakipbekova \\ Laboratory of Physiology and Biochemistry of Microorganisms, RSOE "Institute of Microbiology and \\ Virology" CS MES RK, Republic of Kazakhstan
}

\begin{abstract}
Aspergillus oryzae $M$ was cultivated for 42 days in submerged conditions of growth using new method of fungal cultivation. This method based on immobilizing enzymes producers on solid career in submerged conditions of growth allows to prolong the process of fungal cultivation and to maintain high enzymatic activity for a long period of time. To identify the active isolate formed on the deep fungal mycelium, a selection of a number of isolates was carried out at different periods of submerged cultivation. Aspergillus oryzae M/4 was selected as active isolate with improved extra cellular $\alpha$-amylase activity.
\end{abstract}

Keywords - $\alpha$-amylase, Aspergillus oryzae, submerged fermentation, selection, immobilization.

\section{INTRODUCTION}

Among the industrially important enzymes, amylases are considered to be the most prominent enzymes since they are widely utilized in brewing detergent, and food industries $[1,2]$. In spite of the fact that $\alpha$-amylase can be sourced from plants, animals or microorganisms in the recent past, there has been extensive research in microbial production of $\alpha$-amylase [3, 4]. Microbial enzymes are widely used in industrial processes due to their low cost, large productivity, stability and environmental protection, [5, 6]. Amylases are employed in the starch processing industries for the hydrolysis of polysaccharides such as starch into simple sugar. At least $60 \%$ of the industrial enzymes are obtained from genetically modified microorganisms. However, genetic engineering is long-lasting and requires for special complex techniques [7]. In this regards, the cells immobilization offer a multitude of advantages in enzymes production, such as high metabolic activity and strong resistance to toxic chemicals [8-10].

A method of cultivation of filamentous fungi has been developed as well as devices and equipment for their cultivation [11]. Such devices and equipment prolong producers' cultivation period and create the opportunity to obtain enzymes repeatedly in every 3 days of cultivation. This method is based on immobilization enzymes producers on solid career in submerged conditions of growth. Immobilization has a range of advantages: decreasing the price of the final product, absence of foreign substances, controlled process of enzymegenesis, ability of various enzymes simultaneous production, etc.
During period of fungal cultivation several variants are formed on the immobilized fungal

mycelium. In this paper, screening of alphaamylase high producing strain from Aspergillus oryzae $M$ has been investigated.

\section{MATERIALS AND METHODS}

Enzyme production. For inoculum preparation, $25 \mathrm{ml}$ of sterile distilled water was added to the 5-day-old culture grown on Czapek agar plate and scraped aseptically with inoculating loop. This suspension with spore concentration of 1.3.107 cells $/ \mathrm{ml}$, was used as inoculum for the fungal cultivation. Submerged fermentation was carried out in $750 \mathrm{ml}$ Erlenmeyer flask by taking 100 $\mathrm{ml}$ of mineral salt medium (\%): $\mathrm{NH} 4 \mathrm{NO} 3-0.5$; $\mathrm{KH} 2 \mathrm{PO} 4-0.1 ; \mathrm{MgSO} 4-0.05 ; \mathrm{KCl}-0.05$; FeSO4 - 0.001; maltose - 1.0; starch - 1.0. They were incubated at $30{ }^{\circ} \mathrm{C}$ on a rotary shaker (180 rpm) for 42 days. The growth medium was exchanged at 3-day intervals.

Screening for active variant. To identify the active isolate formed on the substrate, a selection of a number of isolates was carried out at different periods of submerged cultivation. Samples were taken by selecting of the fungal cells from the surface and the depth of the immobilized fungal mycelium. A monosporous suspension was prepared for stirring on an agar plates. The suspension was filtered, diluted with sterile water and plated on Petri dishes with agar medium. In each dish, $0.1 \mathrm{ml}$ of suspension was inoculated and stirred on the surface of the medium with a sterile glass spatula. The Petri dishes were incubated for 5-7 days at $28-30^{\circ} \mathrm{C}$. After incubation, the colonies grown on the plates were counted. The obtained variants were isolated in 
a pure culture. Alpha-amylase enzyme assay. The amylase activity was assayed by spectrohotometric measurement of a starchiodine complex (State Standard of Russian Federation). The reaction mixture $(15 \mathrm{ml})$ consisted of $10 \mathrm{ml}$ of $1 \%(\mathrm{w} / \mathrm{v})$ soluble starch and $0.5 \mathrm{ml}$ appropriately diluted enzyme source in $25 \mathrm{ml}$ of distilled water. After incubation at $30{ }^{\circ} \mathrm{C}$ temperature for $10 \mathrm{~min}$ the reaction was stopped by addition of iodine solution with $0.2 \mathrm{~mol} / \mathrm{dm} 3 \mathrm{HCl}$. Then the enzymatic hydrolysis of starch was determined on spectrophotometer at $670 \mathrm{~nm}$. One unit of the $\alpha$ amylase activity was defined as the amount of enzyme that hydrolyses $1 \mathrm{~g}$ of starch for 1 hour in 30 ${ }^{\circ} \mathrm{C}, \mathrm{pH}$ 4.7. The experiment was carried out in triplicates. The results were expressed as mean \pm standard deviation using Excel 2010.

\section{RESULTS AND DISCUSSION}

A novel immobilization technique was developed by using the cheapest and most easily available cotton material as an immobilizing carrier for absorption of spores of $A$. oryzae $M$, which has been for the first time used for immobilization of microorganisms. Immobilized A. oryzae $M$ on carrier is presented in Figure 1.

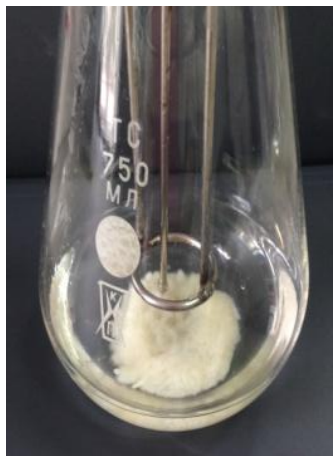

Figure 1: Immobilization of Aspergillus oryzae M

Cultivation period was extended to 42 days. Results show that immobilization procedure has significant effect both on growth and bioactivity of A. oryzae $M$.

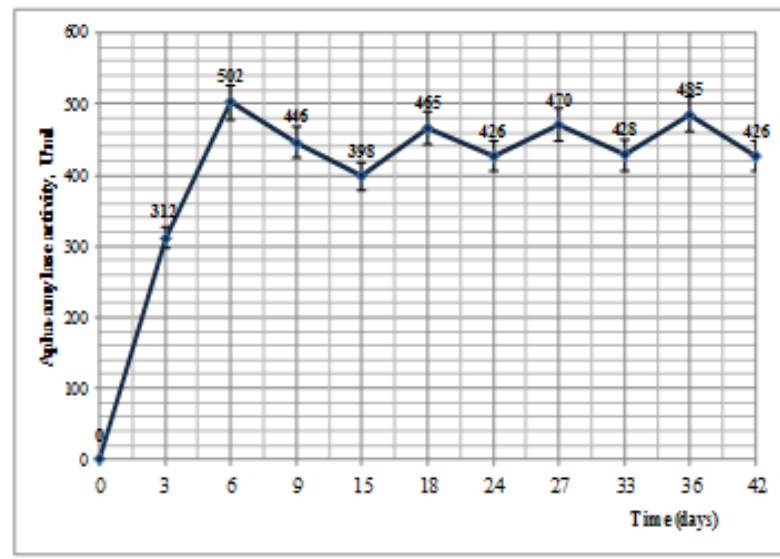

Figure 2: Alpha-amylase production by immobilized Aspergillus oryzae $M$

To select the active isolate formed on the fungal deep mycelium, isolates were taken at different periods of submerged cultivation. On the 6th day of cultivation 4 isolates were selected as well as on the 18th day of cultivation were selected 3 isolates. $\alpha$-amylase activity of 7 isolates was assayed.

Table 1: Enzymatic activity of isolates obtained at different stages of submerged cultivation of Aspergillus oryzae $M$

\begin{tabular}{|c|c|c|}
\hline $\mathrm{NN}$ & Isolate & $\alpha$-amylase activity , U/ml \\
\hline 1 & A. oryzae $M / 1$ & $302 \pm 1,7$ \\
\hline 2 & A. oryzae $M / 2$ & $202 \pm 2,0$ \\
\hline 3 & A. oryzae $M / 3$ & $214 \pm 1,7$ \\
\hline 4 & A. oryzae $M / 4$ & $341 \pm 1,7$ \\
\hline 5 & A. oryzae $M / 5$ & $285 \pm 0,5$ \\
\hline 6 & A. oryzae $M / 6$ & $316 \pm 2,3$ \\
\hline 7 & A. oryzae $M / 7$ & $323 \pm 1,7$ \\
\hline 8 & A. oryzae $M$ & $321 \pm 1,7$ \\
\hline
\end{tabular}

As shown on Table 1, the level of biosynthesis of the $\alpha$-amylase ranged from $202 \mathrm{U} / \mathrm{ml}$ to $341 \mathrm{U} / \mathrm{ml}$. Thus, at the beginning of cells immobilization, the isolate Aspergillus oryzae $M / 4$ was formed with increased enzymatic activity of 341 $\mathrm{U} / \mathrm{ml}$.

\section{Acknowledgements}

This research work was funded by Ministry of Education and Sciences of the Republic of Kazakhstan

\section{REFERENCES}

[1] Rani G., Paresh G., Harapriya M., Vineet K. G., Bhavna C. Microbial $\alpha$-amylases: a biotechnological perspective, Process Biochemistry, 38, 2013, 1599-1616.

[2] Aehle W, Misset O: Enzymes for industrial 
applications. Biotechnology. 2nd edition. Edited by: Rehm HJ, Reed G. Wiley-VCH, Germany, 1999.

[3] David B. Finkelstein. Improvement of enzyme production in Aspergillus. Antonie van Leeuwenhoek Journal of Microbiology, 53, 1987, 349-352.

[4] Khoo SL, Amirul AA, Kamaruzaman M, Nazalan N, Azizan MN. Purification and characterization of $\alpha$-amylase from Aspergillus flavus, Folia Microbiolology, 39, 1994, 392-398.

[5] Burhan A, Nisa U, Gokhan C, Omer C, Ashabil A, Osman G. Enzymatic properties of a novel thermophilic, alkaline and chelator resistant amylase from an alkalophilic Bacillus sp. Isolate ANT-6, Process Biochemistry, 38, 2003, 1397-1403.

[6] Aiyer PV. Amylases and their applications. African Journal of Biotechnology, 4, 2005, 1525-1529.

[7] Sanjai Saxena. Strategies of Strain Improvement of Industrial Microbes, Applied Microbiology, 2015, 155-171.

[8] Guisan J. M. Immobilization of Enzymes and Cells (Third Edition). 2013, P. 115-119.

[9] Konstantin A., Lusta K. C., Whan S., Hee S. P., Dong S. Immobilization of fungus Aspergillus sp. by a novel cryogel technique for production of extracellular hydrolytic enzymes. Proc. Biochemistry, 35, 2000, 1177-1182.

[10] Guisan J. M. Immobilization of Enzymes and Cells (Third Edition), 2013,115-119.

[11] Blieva R. K. An apparatus for the cultivation of microorganisms with filamentous structure. Patent of Kazakhstan № 27164. June 25, 2013. 